\title{
Sehr geehrte Leserinnen, sehr geehrte Leser!
}

Als das für die Energiepolitik verantwortliche Mitglied der Bundesregierung freut es mich, dass Österreich aufgrund internationaler Benchmarks der EU und der Internationalen Energieagentur zu den Ländern mit den geringsten Versorgungsunterbrechungen mit elektrischer Energie zählt.

Trotzdem muss allen Fragen der Sicherheit der Elektrizitätsversorgung und des Engpassmanagements ständig größte Aufmerksamkeit entgegen gebracht werden. Neben dem Monitoring der Versorgungssicherheit durch die Energie-Control $\mathrm{GmbH}$ beschäftigt sich der Elektrizitätsbeirat, der im Bundesministerium für Wirtschaft und Arbeit zu meiner Beratung und zur Beratung der Regulierungsbehörden eingerichtet ist, laufend mit Fragen der Sicherheit der Elektrizitätsversorgung. Umso mehr begrüße ich es, dass im vorliegenden e \& i-Sonderheft eine Reihe ausgewiesener Energieexperten aus Wissenschaft und Praxis den gesamten Themenkomplex „Sicherheit und Engpassmanagement" umfassend bearbeitet. Ich bin überzeugt, dass diese Sammlung von Expertisen den für die Energiepolitik in Österreich auf Bundes-, Landes- und Gemeindeebene Verantwortlichen wertvolle Hinweise für ihre Arbeit zur Gestaltung der Rahmenbedingungen für eine gesicherte Elektrizitätsversorgung geben wird. In diesem Sinne danke ich den Autoren und dem Institut für Elektrische Anlagen und Energiewirtschaft der TU Wien für die Initiative zur Herausgabe dieses Sonderheftes und wünsche ihm bestmögliche Verbreitung.

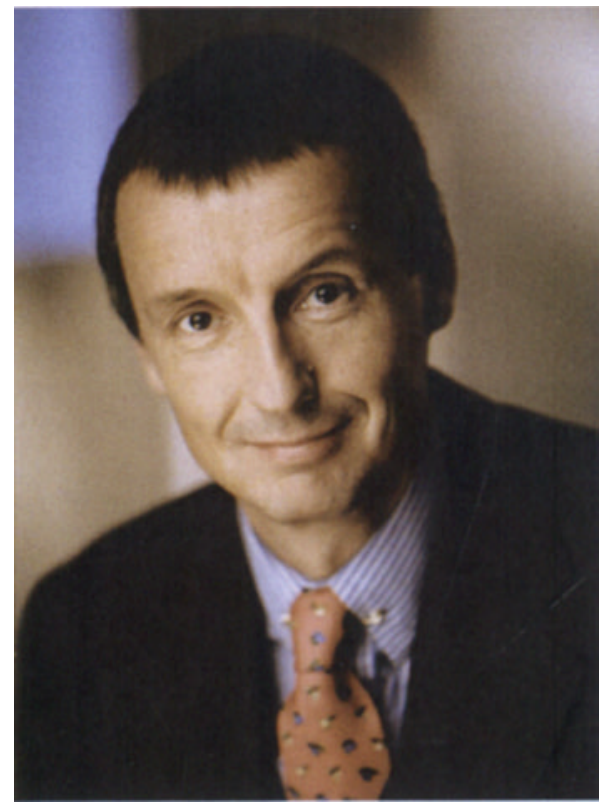

\section{Dr. Martin Bartenstein}

Bundesminister für Wirtschaft und Arbeit 